\title{
Obstetrical and Pediatric Anesthesia
}

Franklin Dexter MD PhD, Alex Macario MD MBA

\section{Optimal number of beds and occupancy to minimize staffing costs in an obstetrical unit?}

Purpose: We describe how the science of analyzing patient arrival and discharge data can be used to determine the optimal number of staffed $O B$ beds to minimize labour costs.

Methods: The number of staffed beds represents a balance between having as few staffed beds as possible to care properly for parturients vs having enough capacity to assure available staff for new admissions. The times of admission and discharge of patients from the OB unit can be used to calculate an average census. From this average census, and the properties of the Poisson distribution, the optimal number of staffed beds can be estimated. This calculation requires specification of the risk of having all in-house and on-call staff caring for patients, such that additional staff are unavailable should another parturient arrive. As an example, patient admission and discharge times were obtained for 777 successive patients cared for at an obstetrical unit. The numbers of patients present in the OB unit each two-hour period were calculated and analyzed statistically.

Principal findings: There was variation in the average census among hours of the day and days of the week. Poisson distributions fit the data for each of four periods throughout the week. Simply benchmarking the current average occupancy and comparing it to a desired occupancy would have been inadequate as this neglected consideration of the risk of being unable to appropriately care for an additional patient.

Conclusions: The optimal number of beds and occupancy of an $\mathrm{OB}$ unit to minimize staffing costs can be determined using straightforward statistical methods.

Objectif : Montrer comment l'analyse des données sur l'arrivée et le départ des patientes peut servir à déterminer le nombre optimal de lits à assigner en obstétrique $(\mathrm{OB})$ en vue de réduire le coût du travail.

Méthode : Le nombre de lits attribués représente un équilibre entre le fait d'avoir le moins de lits possibles pour pouvoir répondre aux besoins des patientes, vs avoir suffisamment de personnel disponible pour de nouvelles patientes. On peut utiliser l'heure d'arrivée et de départ pour le calcul du temps moyen passé en OB. À partir de ce séjour moyen, et des propriétés de la distribution de Poisson, le nombre optimal de lits réservés à l'OB peut être estimé. Ce calcul requiert la spécification du risque d'avoir tout le personnel sur place, en plus du personnel sur appel, affecté aux patientes, de sorte que personne ne sera disponible si une autre patiente se présente. Ainsi, les heures d'admission et de congé ont été obtenues pour 777 patientes successives admises à l'unité obstétricale. Le nombre de patientes présentes à l'unité $\mathrm{OB}$ à chaque heure a été soumis à un calcul et à une analyse statistiques.

Constatations principales : Le nombre moyen variait selon l'heure du jour et le jour de la semaine. Les distributions de Poisson s'accordaient aux données de chacune des quatre périodes de la semaine. Utiliser le temps moyen d'occupation courante comme référence et le comparer à l'occupation souhaitée serait inadéquat, puisqu'on ne tiendrait pas compte du risque de ne pouvoir assurer un traitement approprié à toute patiente supplémentaire.

Conclusion : On peut, dans le but de réduire le coût du personnel, déterminer le nombre optimal de lits et le meilleur taux d'occupation d'une unité d'OB à l'aide de méthodes statistiques simples.

From the Department of Anesthesia, University of Iowa, Iowa City, IA 52242, USA.

Address correspondence to: Dr. Franklin Dexter. Phone 319-330-7219; FAX 603-947-1304; E-mail franklin-dexter@uiowa.edu Financial disclosure: Franklin Dexter is employed by the University of Iowa, in part as a consultant to anesthesia groups, companies, and hospitals.

Accepted for publication October 13, 2000. 
S

TAFFING of obstetrical (OB) units is unique because all parturients seeking admission must receive care. Unlike postoperative surgical wards, the arrival of most parturients is random. As such, OB units often have empty, but staffed, beds.

Obstetrical anesthesiologists, obstetricians, and OB nurse managers need to work together to ensure that there are a sufficient number of staffed beds (i.e., staff) to care for patients on the $\mathrm{OB}$ unit. We define " $\mathrm{OB}$ unit" as the facility at which parturients labour and deliver. A staffed bed is the combination of a physical location (e.g., labour room) and appropriate nurse and physician coverage. If there are too few staffed beds, then parturients may not receive the care they need. If there are too many staffed beds, then labour costs for the $\mathrm{OB}$ unit may increase unnecessarily.

The goal of this article was to review the science of using $\mathrm{OB}$ patient arrival and discharge data to determine the optimal number of staffed OB beds, given that $\mathrm{OB}$ managers aim to achieve a balance between having as few staffed beds as possible to care properly for parturients $v s$ having enough capacity to assure available staff for new admissions. " This "staffing" decision is a long-term decision, meaning that it is usually made no more often than every 6 to 12 months. We do not consider in this paper the "scheduling" decision, which determines when each $\mathrm{OB}$ unit nurse is to report to work, and which on an $\mathrm{OB}$ unit may be adjusted hourly.

Reason for focusing on the number of staffed beds The workload of an OB service depends on both the patients' medical risks and the number of staffed beds on the OB unit. Provided that the OB unit has sufficient capacity to assure available staff for new admissions, a patient's acuity does not affect the time of day or date of her admission to the OB unit. The acuity of patients already admitted to the OB unit does not impact on the timing of admission of new patients. Finally, the acuity of one patient does not affect how long another patient remains on the $\mathrm{OB}$ unit. Consequently, the workload of the OB service is proportional to the appropriate number of $\mathrm{OB}$ beds (i.e., the number that need to be staffed). This is why determining the appropriate number of staffed beds is essential to maximizing the productivity of the $\mathrm{OB}$ unit staff.

Obstetric unit occupancy

The "average census" of an $\mathrm{OB}$ unit is a ratio. ${ }^{2}$ It specifies the average number of patients present on the $\mathrm{OB}$ unit at any one time. The numerator is the sum, among patients cared for during a one-year period, of the hours that each patient spends in the OB unit. The denominator equals the total number of hours in one year or $8,760 \mathrm{hr}$, where $8,760=(365$ days per year $) \times(24$ hours per day). For example, if the total patient hours during a year was 43,800 , then the average census would be five patients, where five patients $=(43,800$ patient hours in a year $) \div(8,760$ hours in a year $)$.

The "average percentage occupancy" is the percentage of time that a staffed bed is being used. This is a measure of the efficiency of an OB unit. ${ }^{2}$ The average percentage occupancy is calculated by dividing the average census by the average number of staffed $\mathrm{OB}$ beds. For example, the average number of staffed OB beds may equal 8.5 beds. In a simple example, 8.5 staffed beds would be calculated as: [ 8 beds $24-\mathrm{hr}$ a day $)+(2$ beds for patients admitted to undergo a scheduled procedure such as elective Cesarean section) $\times(5$ days each week used for scheduled procedures $) \times$ ( 8 hours a day during which scheduled procedures are performed $) \div((7$ days a week $) \times(24$ hours a day $))]$. If the average census was five patients and there was an average of 8.5 beds, then, the percentage occupancy would be $59 \%$.

For purposes of calculating occupancy, "staffed beds" are the only available beds. For example, if the $\mathrm{OB}$ unit is particularly busy, then an additional nurse on-call could come in from home sufficiently early that he or she would be present if needed for a task such as performing an emergency Cesarean section. Likewise, a nurse manager may care for patients instead of working in an administrative office. However, for these providers to be available immediately for service in the $\mathrm{OB}$ unit, they would not be able to perform other patient care activities. As such, the beds that they cover are considered to be "staffed beds."

Problem in using peer OB units to benchmark occupancy

Whether an OB unit has "too many" staffed beds to care for parturients or too few staffed beds can be assessed by measuring the actual average percentage occupancy and then comparing it to a benchmark ${ }^{3}$ from similar, peer units. ${ }^{3,4}$

In our previous example, the OB unit has a $59 \%$ occupancy. Let us suppose that benchmarked similar OB units have an average occupancy of $67 \%$. Then, managers of our example OB unit may aim to decrease the average number of staffed beds from 8.5 beds to approximately 7.5 beds, where $7.5=((59 \% / 67 \%) \times$ (8.5 beds)).

The average occupancy model assumes that peer $\mathrm{OB}$ units have a nearly equal risk of not having enough staff 
TABLE I The optimal number of beds that needs to be staffed depends on the risk taken by an $\mathrm{OB}$ unit that all in-house and oncall staff are caring for patients

\begin{tabular}{lllll}
\hline & \multicolumn{2}{c}{ Risk $\leq 5 \%$} & \multicolumn{2}{c}{ Risk $\leq 1 \%$} \\
Average & Minimum & Average \\
census & staffed * beds & occupancy & Minimum & Average \\
staffed * beds & occupancy (\%) \\
\hline 2 & 5 & 40 & 6 & 33 \\
3 & 6 & 50 & 8 & 38 \\
4 & 8 & 50 & 9 & 44 \\
5 & 9 & 56 & 11 & 45 \\
6 & 10 & 60 & 12 & 50 \\
7 & 12 & 58 & 14 & 50 \\
8 & 13 & 62 & 15 & 53 \\
9 & 14 & 64 & 17 & 53 \\
10 & 15 & 67 & 18 & 56 \\
11 & 17 & 65 & 19 & 58 \\
12 & 18 & 67 & 21 & 57 \\
13 & 19 & 68 & 22 & 59 \\
14 & 20 & 70 & 23 & 61 \\
15 & 22 & 68 & 25 & 60 \\
\hline
\end{tabular}

* Number of OB staff nurses planned for these beds depends on the average nurse to patient ratio. ${ }^{18}$

available for a newly admitted OB patient. For example, an $\mathrm{OB}$ unit may maintain a high (e.g., 90\%) occupancy by having so few beds that the OB unit is often "full" such that all in-house and on-call staff are caring for patients. This $\mathrm{OB}$ unit would not serve as a suitable "peer" comparison $\mathrm{OB}$ unit to an $\mathrm{OB}$ unit which chooses to have a lower risk that all in-house and on-call staff are caring for patients. This is analogous to not having available, appropriate OR personnel to handle a second emergency surgery case simultaneously at night if such a patient were to need care.

In order to match appropriately an $\mathrm{OB}$ unit with a benchmark OB unit, the risk that all in-house and oncall staff are caring for patients and cannot appropriately care for an additional patient must be measured for each OB unit. The average occupancy model to estimate staffing needs is inadequate because it neglects computing this risk. ${ }^{4}$ As such, the average occupancy model has been rejected for use in statewide planning efforts. ${ }^{5}$

Measuring the risk that all in-house and on-call staff are working and are not able to care appropriately for an additional patient requires that the Poisson probabilistic analyses, described in the next section, be used.

Risk analysis of having a full unit such that all inhouse and on-call staff are working and are not able to care appropriately for an additional patient

If the average percentage occupancy were $100 \%$, then the risk of having an $\mathrm{OB}$ unit without any free avail- able staff would also be $100 \%$. This "risk" of having a full unit refers to the chance that if a new patient were to arrive, all in-house and on-call staff would already be busy caring for patients.

The risk of having a "full" unit, at any given time, can be calculated by making the assumption that the number of patients present in the $\mathrm{OB}$ unit follows a Poisson distribution. ${ }^{3}$ Clinical studies have found this assumption to hold. ${ }^{1,3,6}$ For example, Thompson et $a l^{6}$ measured the number of patients present in an $\mathrm{OB}$ unit each hour during 30 consecutive days. The actual distribution for the number of patients present at each hour in that $\mathrm{OB}$ unit was plotted and found to match the distribution predicted assuming a Poisson distribution. ${ }^{6}$ We provide an example of such an analysis, including figures, below in the "Application of the analysis ..." section.

The numbers of patients in an $\mathrm{OB}$ unit at any one time have been shown to follow Poisson distributions, ${ }^{1,3,5,6}$ because the following three criteria required for Poisson distributions are reasonable for most $\mathrm{OB}$ units:

1. How long one patient remains in the $\mathrm{OB}$ unit does not affect how long another patient remains in the same unit. ${ }^{7}$ This assumption will hold provided that the OB unit has a sufficient number of beds so that patients are not routinely discharged earlier than desired in order to make room for other patients.

2 . The time of day and date of a patient's admission to the OB unit is not affected by how long the patient would be expected to remain on the $\mathrm{OB}$ unit.

3 . The length of time between successive patients' admissions is independent. ${ }^{6}$ Provided that the average census of patients scheduled for admission to the OB unit is a small percentage of the average census, this assumption is probably reasonable. ${ }^{3,6}$ Obstetrical units with an unusually high percentage of scheduled admissions (e.g., > 15\%) may need to use a more sophisticated method of analysis (see "Special situations ..." section below).

The objective in calculating the risk of all in-house and on-call staff being used and not able to care for an additional patient is to choose the number of beds to staff which maximizes the average percentage occupancy while at the same time not exceeding some predetermined risk of having all available staff working. ${ }^{2,3,8}$ To do this requires calculation of the cumulative distribution function for the Poisson distribution. This can be done using the "Poisson" function in Excel ${ }^{\circledR}$ (Microsoft, Redmond, WA). We used this function to create Table I.

To use Table I, the obstetricians, anesthesiologists, and $\mathrm{OB}$ nurse managers working in an $\mathrm{OB}$ unit must 

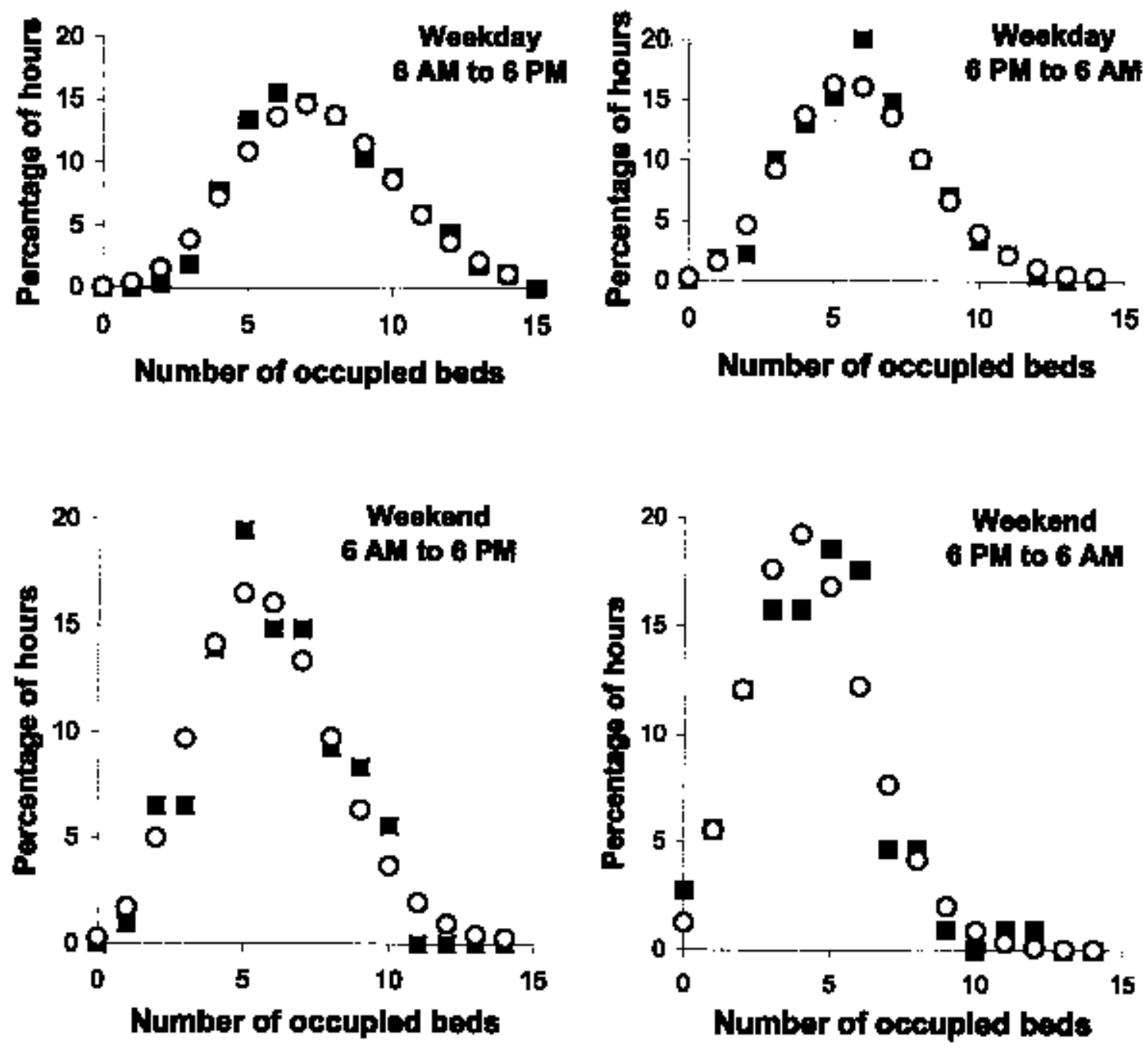

FIGURE Analysis of admission and discharge times of parturients from Stanford University Medical Center's obstetrical unit for October and November 1999. Open circles are expected values from the fit of the Poisson distribution given in columns 3-5 of Table II. Filled squares represent the corresponding observed (actual) values. To obtain these values, patient admission and discharge times from the obstetrical unit were tracked. Using two months of data, the number of patients present in the obstetrical unit each hour was calculated as given in Table II. Because of variation in the average census among hours of the day and days of the week, separate analyses were performed for the four time periods listed in column 1 of Tables II and III.

decide on the level of risk that they are willing to accept for the $\mathrm{OB}$ unit not having enough staff to care appropriately for another patient. ${ }^{2}$ Ideally, this risk would be much less than $1 \%$. However, this objective is not realistic, as it would require a very low average percentage occupancy.

A higher risk of having all in-house and on-call staff working and not able to care for an additional patient (e.g., 10\% of hours) may not allow for enough excess capacity to handle those rare, "busy" days on the OB unit when there are more patients than the staff can handle safely.

The published risks of an OB unit being "full," (i.e., no additional staff available to care for another parturient if one were to arrive) include $1 \%,{ }^{5,9} 2 \%,{ }^{6}$ and ${ }^{10,11} 5 \%$ of hours. For this reason, we included $1 \%$ and $5 \%$ in Table I. Generally, if a risk of $5 \%$ were considered to be satisfactory for a densely populated area with several OB 
TABLE II Stanford University Medical Center's OB unit's patient admission and discharge times fit Poisson distributions

\begin{tabular}{|c|c|c|c|c|c|}
\hline \multirow[b]{2}{*}{ Period* } & \multirow[b]{2}{*}{$\begin{array}{l}\text { Number of two } \\
\text {-hour periods } \\
\text { used in analysis }(N)\end{array}$} & \multicolumn{2}{|c|}{$\begin{array}{l}\text { Criteria used to determine if data from } \\
\text { each time period fit a Poisson distribution }\end{array}$} & \multicolumn{2}{|c|}{$\begin{array}{l}\text { Characteristics of the predicted Poisson } \\
\text { distributions obtained from the actual data }\end{array}$} \\
\hline & & $\begin{array}{l}\text { Actual vs predicted\$ differences } \\
\text { in percentages of periods with } \\
\text { number of occupied beds }\end{array}$ & $\chi^{2}$ test II & Average census & $\begin{array}{l}\text { Upper 95\% } \\
\text { confidence bound } \\
\text { of average census }\end{array}$ \\
\hline $\begin{array}{l}6 \text { a.m. to } 6 \text { p.m. ("day shift") } \\
\text { Monday through Friday }\end{array}$ & $270 \dagger$ & Mean difference $=1.3 \%$ & $P=0.53$ & 7.5 & 7.8 \\
\hline $\begin{array}{l}6 \text { p.m. to } 6 \text { a.m. ("night shift") } \\
\text { Monday through Friday }\end{array}$ & $270 \dagger$ & Mean difference $=1.7 \%$ & $P=0.50$ & 5.9 & 6.2 \\
\hline $\begin{array}{l}6 \text { a.m. to } 6 \text { p.m. (“day shift”) } \\
\text { Saturday \& Sunday }\end{array}$ & $108 \ddagger$ & Mean difference $=1.5 \%$ & $P=0.89$ & 5.8 & 6.2 \\
\hline $\begin{array}{l}6 \text { p.m. to } 6 \text { a.m. ("night shift") } \\
\text { Saturday \& Sunday }\end{array}$ & $108 \ddagger$ & Mean difference $=1.4 \%$ & $P=0.40$ & 4.4 & 4.7 \\
\hline
\end{tabular}

* Time periods start at 6 a.m. as women at Stanford are frequently admitted for induction of labour at 6:30 a.m.

$\dagger 270=(6$ two-hour periods per day $) \times(5$ days per week $) \times(9$ weeks $)$

$\ddagger 108=(6$ two-hour periods per day $) \times(2$ days per week $) \times(9$ weeks $)$

$\$$ If actual (observed) percentages equaled predicted percentages, the mean differences would equal $0 \%$. Each two-hour "period" listed in column 2 corresponds to one pair of symbols in Figure 1. The actual vs predicted differences in percentages of periods (column 3 ) correspond to the differences between the open circles and filled squares in Figure 1 .

If For the $\chi^{2}$ test, a $P>0.05$ suggests an acceptable fit between actual data and that predicted by a Poisson distribution.

TABLE III The number of OB beds that need to be staffed at Stanford depending on the level of risk of all in-house and on-call staff caring for patients (i.e., no additional staff available for another patient)

\begin{tabular}{|c|c|c|c|c|c|c|}
\hline \multirow[b]{2}{*}{ Time period } & \multicolumn{2}{|c|}{$\begin{array}{l}\text { Fit to Poisson distribution } \\
\text { as given in Table II }\end{array}$} & \multicolumn{2}{|c|}{$\begin{array}{l}\text { Number of staffed beds needed during } \\
\text { each 12-hour shift if acceptable risk }=5 \%\end{array}$} & \multicolumn{2}{|c|}{$\begin{array}{l}\text { Number of staffed beds needed during } \\
\text { each 12-hour shift if acceptable risk }=1 \%\end{array}$} \\
\hline & $\begin{array}{l}\text { Average } \\
\text { census }\end{array}$ & $\begin{array}{l}\text { Upper } 95 \% \\
\text { confidence bound }\end{array}$ & $\begin{array}{l}\text { From average } \\
\text { census }\end{array}$ & $\begin{array}{l}\text { From upper 95\% } \\
\text { confidence bound }\end{array}$ & $\begin{array}{l}\text { From average } \\
\text { census }\end{array}$ & $\begin{array}{l}\text { From upper } 95 \% \\
\text { confidence bound }\end{array}$ \\
\hline \multicolumn{7}{|l|}{6 a.m. to 6 p.m. ("day shift") } \\
\hline $\begin{array}{l}\text { Monday through Friday } \\
6 \text { p.m. to } 6 \text { a.m. ("night shift") }\end{array}$ & 7.5 & 7.8 & 12 & 15 & 13 & 15 \\
\hline $\begin{array}{l}\text { Monday through Friday } \\
6 \text { a.m. to } 6 \text { p.m. ("day shift") }\end{array}$ & 5.9 & 6.2 & 10 & 12 & 11 & 13 \\
\hline $\begin{array}{l}\text { Saturday \& Sunday } \\
6 \text { p.m. to } 6 \text { a.m. ("night shift") }\end{array}$ & 5.8 & 6.2 & 10 & 12 & 11 & 13 \\
\hline Saturday \& Sunday & 4.4 & 4.7 & 8 & 10 & 9 & 10 \\
\hline
\end{tabular}

units, a risk of $0.5 \%$ might be more appropriate for a sparsely populated region with only one $\mathrm{OB}$ unit. ${ }^{2}$

To use Table I, the average census of the OB unit also has to be measured. A characteristic of the Poisson distribution is that the average census is the only parameter necessary to describe the distribution.

When the risk and average census have been specified, Table I can be used to calculate the maximum average occupancy that the $\mathrm{OB}$ unit can achieve. For example, if the average census of an $\mathrm{OB}$ unit is 6 , and the risk of having all in-house and on-call staff caring for patients is less than $5 \%$, then the minimum number of staffed beds is 10 and the maximum achievable average occupancy is $60 \%$. The number of OB staff planned for these beds depends on the average nurse to patient ratio and physician to patient ratio. The analysis in Table I also shows that with a 5\% risk and typical census levels in the United States, average occupancy rates will not exceed $65 \%$. Analysis using sophisticated computer simulation models arrives at the same conclusion. ${ }^{11}$

There are economic advantages of having a larger average census. ${ }^{5}$ Provided that the risk of having a situation where all in-house and on-call staff are caring for patients is kept constant, an increase in the average census permits a higher percentage occupancy (Table I). ${ }^{3,5}$ This means that $\mathrm{OB}$ units with more patients per day can be more productive than lower volume units. For example, an $\mathrm{OB}$ unit with an average census of four patients needs staff for at least nine beds if the risk of having all in-house and on-call staff working (i.e., no additional available staff for the $\mathrm{OB}$ unit if another 
patient arrives) is to be maintained at less than $1 \%$ of hours (Table I). The OB unit's mean occupancy must then be less than $44 \%$.

In contrast, an $\mathrm{OB}$ unit with an average census of 15 patients could have an average occupancy as high as $60 \%$ while maintaining the same risk. The prediction that $\mathrm{OB}$ units with higher average censuses have higher average percentage occupancies has been confirmed in observational studies comparing occupancy rates of $\mathrm{OB}$ units in Connecticut. ${ }^{10}$

Variability hour to hour in the average census on the $\mathrm{OB}$ unit

Before fitting census data to a Poisson distribution, variation in the average number of patients on the $\mathrm{OB}$ unit each hour should be considered. If there are differences in the number of patients in the $\mathrm{OB}$ unit, the analysis needs to compensate for this so that the acceptable risk of not having additional OB staff is maintained at all times.

Birth rates can vary among times of the day. For example, in Calgary, Canada the birth rate is above average between 7 a.m. and 6 p.m., in part because of the scheduling of patients who are to have induction of labour or have elective Cesarean sections during these hours. ${ }^{12}$

Birth rates can also vary among days of the week, because there may be fewer patients with induced deliveries and Cesarean deliveries on weekends compared to the number on weekdays. ${ }^{13}$ For example, in the United States, Saturday and Sunday have lower birth rates than Monday through Friday. ${ }^{13}$ There is more variation in birth rates among days of the week ( $15 \%$ ) than among months of the year $(4.9 \%) .{ }^{13}$ Since most $\mathrm{OB}$ units will have little monthly variation in birth rates, reevaluating staffing every two to three months without considering systematic monthly variation is generally appropriate.

Application of the analysis: example using data from Stanford University Medical Center

We provide an example of how to apply these analyses. Patient admission and discharge times of the 777 patients cared for at Stanford University Medical Center's obstetrical unit from October 1, 1999 to November 30, 1999 were tracked. ${ }^{14}$ Patients were discharged to a postpartum ward after delivery. The number of patients present in the $\mathrm{OB}$ unit in each two-hour period was calculated and analyzed statistically (Figure 1, Tables II,III).

There was variation in the average census among hours of the day and days of the week. We found that Poisson distributions fit the data for weekdays 6 a.m. to
6 p.m., weekdays 6 p.m. to 6 a.m., weekends 6 a.m. to 6 p.m., and weekends 6 p.m. to 6 a.m., based on ${ }^{2}$ tests and the actual (observed) versus predicted differences in percentages of periods with specified numbers of occupied beds (Figure 1, Table II). To maintain a 5\% risk, 15 staffed beds were needed for parturients weekdays 6 a.m. to 6 p.m., 12 staffed beds were needed weekdays 6 p.m. to 6 a.m., 12 staffed beds were needed weekends 6 a.m. to 6 p.m., and 10 staffed beds weekends 6 p.m. to 6 a.m. (Table III).

Special situations where the Poisson derived analyses may be inadequate and computer simulation would be required to analyze staffed bed requirements The methods described above may not be sufficient for some $\mathrm{OB}$ units. Below, we provide a summary of some more sophisticated analyses to assist $\mathrm{OB}$ unit managers. For purposes of this discussion, we consider a "birthing room" to be a location in which the mother receives all obstetrical services, including labour, delivery, recovery, and postpartum care.

1. The analysis we described above assumed that the number of patients present on the $\mathrm{OB}$ unit did not affect the timing of admissions. Some OB units have both birthing rooms and conventional (older) patient rooms. ${ }^{2}$ Since some patients prefer birthing rooms to older conventional rooms, if a staffed birthing room is not available, patients who are scheduled for induction of labour may delay their admission. ${ }^{1}$ If this were the case (i.e., the $\mathrm{OB}$ unit has both birthing and conventional rooms, and patients prefer one over the other), then the analyses presented above may yield inaccurate results. In order to obtain accurate risk and staffing results when patients delay their admissions, a computer program would need to be used to "act like" (simulate) the system of interest (the $\mathrm{OB}$ unit).

2. Some OB units maintain a high occupancy by keeping $\mathrm{OB}$ unit beds full with gynecology patients. At such $O B$ units, patients are transferred to other hospital units when an $\mathrm{OB}$ patient seeks admission and the OB unit is "full". ${ }^{9}$ This is another example where the Poisson derived analyses above may be inadequate and computer simulation would be required to analyze bed requirements. 9

3 . In an effort to increase the number of referrals of parturients to an $\mathrm{OB}$ unit, hospitals may build more attractive "birthing suites" by combining previously existing older hospital rooms. As more of the postpartum care occurs on the $\mathrm{OB}$ unit, length of stay on the $\mathrm{OB}$ unit will increase, while hospital length of stay remains unchanged. Computer simulation can be used to predict the impact of building birthing suites on staffing. 
4. The Poisson analysis that we described above assumes that the percentage of patients whose times of admission are scheduled by the OB unit (vs unscheduled admissions) is small (e.g., 10\%). Scheduled admissions would include women for induction of labour or elective Cesarean section. If an $\mathrm{OB}$ unit has many patients that are scheduled admissions, scheduling rules have been developed that can decrease $\mathrm{OB}$ staffing costs substantially by decreasing hour to hour variability in the $\mathrm{OB}$ unit census. ${ }^{2,15,16}$ Scheduled admissions would be postponed (e.g., for an hour or two) if the $\mathrm{OB}$ unit census exceeds a certain number of patients, the value of which is calculated using the statistical methods. ${ }^{15,16}$

5. Some OB units may find that average census level varies among months and years depending on variation in how aggressively the hospital advertises the $\mathrm{OB}$ unit in the local community. Similarly, an $\mathrm{OB}$ unit may have progressively increasing or decreasing average census levels depending on changes in managed care contracts or obstetrical groups' practices. More sophisticated statistical methods than those we have reviewed have been developed to predict staffing needs under these circumstances. ${ }^{17}$

\section{Summary}

To determine the optimal number of beds and occupancy of an $\mathrm{OB}$ unit to minimize staffing costs, the $\mathrm{OB}$ director must work to assure that there are as few staffed beds as needed to care for the patients. The measured average percentage occupancy should not simply be compared with a desired occupancy obtained from benchmarking studies. Instead, the times of admission and discharge of patients from the OB unit should be used to calculate an average census. From this average census, and the properties of the Poisson distribution, the optimal number of staffed beds can be estimated. This calculation requires the $\mathrm{OB}$ unit to define the risk of having all in-house and on-call staff caring for patients. We showed how this analysis can be performed using a commonly available spreadsheet or statistics package.

\section{References}

1 Cormack RS. Predicting the obstetric work-load.

Anaesthesia 1984; $39: 552-3$.

2 Shonick W. A stochastic model for occupancy-related random variables in general-acute hospitals. J A S A 1970; 65: 1474- 500.

3 Blumberg MS. "DPF concept" helps predict bed needs. Mod Hosp 1961; 97: 75-81.

4 Huang $X-M$. A planning model for requirement of emergency beds. IMA J Math Appl Med Biol 1995; 12: $345-53$.
5 Western Wisconsin Health Systems Agency Hospital Bed Need Task Force Final Report. 1981 Mar. 77. Sponsored by Bureau of Health Planning, Hyattsville, MD.

6 Thompson JB, Avant OW, Spiker ED. How queuing theory works for the hospital. Mod Hosp 1960; 94: 75-8.

7 Pike MC, Proctor DM, Wyllie JM. Analysis of admissions to a casualty ward. Br J Prev Soc Med 1963; 17: 172-6.

8 Thompson JD, Fetter RB. The economics of the maternity service. Yale J Biol Med 1963; 36: 91-103.

9 Vassilacopoulos $G$ A simulation model for bed allocation to hospital inpatient departments. Simulation $1985 ; 45: 233-41$.

10 McClain JQ A model for regional obstetric bed planning. Health Serv Res 1978; 12: 378- 94.

11 Gupta $T$. Use of simulation technique in maternity care analysis. Computers Ind Eng 1991; 21:489-93.

12 Wang ZJ, Avard D, Abernathy T, Nimrod C Birth patterns: are the Chinese in Guangzhou City different? Int J Gynecol Obstet 1988; $27: 25-35$.

13 Ventura SJ, Martin JA, Curtin SC, Mathews TJ. Report of final natality statistics, 1995. Monthly vital statistics report. Hyattsville, Maryland: National Center for Health Statistics 1997; 45(Suppll1): 39.

14 Lamiell JM. Modeling intensive care unit census. Military Med 1995; 160: 227-32.

15 Young JP. Administrative control of multiple-channel queuing systems with parallel input streams. Oper Res 1966; 14: 145- 56.

16 Young JP. Stabilization of inpatient bed occupancy through control of admissions. Hospitals 1965; 39: $41-8$.

17 Buffa ES, Cosgrove MJ, Luce BJ. An integrated work shift scheduling system. Decision Sci 1976; 7: 620- 30.

18 Jenkin-Cappiello E. Oh baby! A labor and delivery staffing system measures patient census and acuity. Nurs Manage 2000; 31: 35- 7 . 